\title{
Acute rheumatic fever and rheumatic heart disease in Fiji: prospective surveillance, 2005-2007
}

Andrew C Steer, Joseph Kado, Adam W J Jenney, Michael Batzloff, Lepani Waqatakirewa, E Kim Mulholland and Jonathan R Carapetis

$\mathrm{R}$ ates of acute rheumatic fever (ARF) have remained stable in many developing countries, despite a dramatic decline in the incidence of ARF in industrialised countries in the 20th century. ${ }^{1}$ Globally, it is estimated that more than 330000 cases of ARF occur each year in children aged 5-14 years and that over 95\% of these cases are found in less developed countries. ${ }^{1}$ Although there are ample data to support the claim that ARF has virtually disappeared from industrialised nations, there are fewer data from low- and middle-income nations. ${ }^{1,2}$

The most comprehensive recent descriptions of the clinical manifestations of ARF come from outbreaks in the United States and from the Australian Indigenous population in the Northern Territory; there are few descriptions of the clinical profile of ARF in less developed nations. ${ }^{3,4}$ Likewise, there are few descriptions of the clinical presentation of rheumatic heart disease (RHD) in developing countries. ${ }^{5}$ We therefore designed a study to characterise the clinical epidemiology of patients admitted to hospital with ARF and RHD in Fiji. This study was part of a series of studies designed to estimate the burden of group A streptococcal disease in Fiji and to prepare for potential clinical trials of group A streptococcal vaccines.

\section{METHODS}

A prospective enhanced surveillance study was conducted at the Colonial War Memorial Hospital in Fijis capital, Suva, over the 23-month period from 5 December 2005 to 5 November 2007. The hospital serves the Central Division of Fiji, which in 2007 had a population of 340843 people, predominantly comprising the two main ethnic groups of Indigenous Fijians (213515) and Indo-Fijians (102 799). ${ }^{6}$

\section{Surveillance and case definition}

\section{Acute rheumatic fever}

We used the 2002-2003 World Health Organization revision of the Jones Criteria for the diagnosis of ARF., ${ }^{7,8}$ Patients were defined as having recurrent ARF if they had a bona fide past history of ARF or documented established RHD. We used 80\%

\section{ABSTRACT}

Objectives: To determine the incidence and clinical features of acute rheumatic fever (ARF) in Fiji, and the clinical features of patients presenting to hospital in Fiji with rheumatic heart disease (RHD).

Design and setting: A prospective surveillance study at the Colonial War Memorial Hospital in Suva over a 23-month period from December 2005 to November 2007.

Main outcome measures: Incidence of ARF; clinical features of ARF and RHD.

Results: The average annualised incidence of definite cases of ARF in children aged 5-15 years was 15.2 per $100000(95 \% \mathrm{Cl}, 9.0-22.6)$. The clinical features of ARF were similar to those in classic descriptions. Carditis was very common, occurring in $79 \%$ of cases. There were 103 admissions for RHD in which detailed information was collected, with the most common reason for admission being cardiac failure (51\%). The median age at admission with RHD was 26.8 years, and there were 10 deaths of patients with RHD (case fatality rate, 9.7\%).

Conclusions: Although apparently declining in incidence since the middle of the 20th century, ARF remains a significant health problem in Fiji. RHD affects young people, leading to premature morbidity and mortality. There is an urgent need for effective control of ARF and RHD in Fiji.

MJA 2009; 190: 133-135

upper limit of normal cut-off values for both antistreptolysin $\mathrm{O}(238 \mathrm{IU} / \mathrm{mL})$ and antideoxyribonuclease B (499 IU/mL) titres that were established specifically for the Fijian population in a recent study (for 515-year-olds; unpublished data). We also considered a separate category of "probable ARF" for patients who fulfilled the clinical criteria for ARF but did not have raised antistreptococcal antibody titres in a single blood sample as defined by our upper limit.

\section{Rheumatic heart disease}

Any patient admitted with a complication of RHD as the primary reason for admission was eligible for enrolment in the study. Complications of RHD were any one or more of congestive cardiac failure, infective endocarditis, atrial fibrillation, stroke or recurrent ARF. We also included patients in whom a new murmur was detected when the reason for admission was for confirmation of the diagnosis of RHD.

\section{Statistical analysis}

We used population figures from the 2007 national census ${ }^{6}$ as the basis for denominator calculations for ARF incidence. For comparisons between sexes and ethnic groups, we used incidence rate ratios for ARF, and population-adjusted relative risk for RHD.
Data were analysed using Stata, version 10.0 (StataCorp, College Station, Tex, USA).

\section{Ethics approval}

Ethics approval was obtained from the Fiji National Research Ethics Review Committee, the Fiji National Heath Research Committee, and the Human Research Ethics Committees of the University of Melbourne and the Queensland Institute of Medical Research. Written informed consent was obtained from all adults. Children were enrolled once written consent from a parent or guardian was obtained, in addition to written assent provided by individual children if they were aged 10 years or older.

\section{RESULTS}

\section{Acute rheumatic fever}

There were 37 cases of ARF ( 33 definite and four probable) detected during the study period. The 33 definite cases comprised 20 initial episodes and 13 recurrent episodes (nine with coexisting established RHD, and four with a past history of ARF but no RHD); the recurrence rate of ARF was therefore $39 \%$.

The median age at diagnosis of definite ARF was 10.4 years (interquartile range [IQR], 8.7-14.3 years). The oldest patient with an episode of definite ARF was 42 years 


\section{Demographic features of patients presenting with definite acute rheumatic fever to the Colonial War Memorial Hospital, December 2005 to November 2007}

\begin{tabular}{|c|c|c|c|}
\hline \multicolumn{2}{|l|}{ All ages } & \multicolumn{2}{|c|}{$5-15$ years of age } \\
\hline $\begin{array}{l}\text { No. of } \text { Incidence per } \\
\text { cases } 100000(95 \% \mathrm{Cl})\end{array}$ & $\begin{array}{l}\text { Incidence rate } \\
\text { ratio }(95 \% \mathrm{Cl})\end{array}$ & $\begin{array}{l}\text { No. of } \quad \text { Incidence per } \\
\text { cases } 100000(95 \% \mathrm{Cl})\end{array}$ & $\begin{array}{l}\text { Incidence rate } \\
\text { ratio }(95 \% \mathrm{Cl})\end{array}$ \\
\hline
\end{tabular}

\section{Sex}

$\begin{array}{lcccccc}\text { Female } & 16 & 5.0(2.9-8.2) & 1.0(0.5-2.1) & 12 & 15.5(8.0-27.0) & 1.0(0.4-2.5) \\ \text { Male } & 17 & 5.1(3.0-8.2) & & 12 & 14.9(7.7-26.0) & \\ \text { Ethnicity } & & & & & & \\ \begin{array}{l}\text { Indigenous } \\ \text { Fijian }\end{array} & 26 & 6.4(4.2-9.4) & 2.2(0.9-6.1) & 17 & 16.4(9.6-26.3) & 1.3(0.5-3.7) \\ \text { Other races } & 7 & 2.5(0.9-5.4) & & 7 & 12.8(5.1-26.3) & \end{array}$

old (recurrent episode), and the youngest was 4.6 years old (initial episode). The average annualised incidence of definite ARF in children aged $5-15$ years was 15.2 per 100000 (95\% CI, 9.0-22.6); when probable cases were included, the incidence was 17.7 per 100000 (95\% CI, 11.8-25.6). The incidence of ARF was higher in Indigenous Fijians (Box 1). The clinical features of all patients presenting with definite ARF are summarised in Box 2.

\section{Rheumatic heart disease}

There were 106 patients admitted with RHD as the primary reason for admission. Three patients did not give consent, so detailed demographic and clinical information was available for 103 patients.

The median age of patients presenting with RHD was 26.8 years (IQR, 19.3-42.0 years). There were 31 patients (30\%) aged less than 20 years, and the youngest patient was aged 6 years. Forty patients (38\%) with no past history of RHD were diagnosed with RHD for the first time (median age, 24.7 years; IQR, 17.3-37.2 years). There were 10 deaths, representing an inhospital fatality rate of $9.7 \%$. The youngest patient who died was 7.6 years old (median age at death, 33.1 years; IQR, 20.1-42.7 years). The relative risk of admission for RHD for females compared with males was 2.5 (95\% CI, 1.63.8 ), and the relative risk for Indigenous Fijians compared with other races was 1.9 (95\% CI, 1.2-2.9).

The clinical features of patients with RHD are summarised in Box 3. Of note, there were 24 pregnant women admitted with RHD. Using obstetric data from the Colonial War Memorial Hospital in 2006 (Dr James Fong, Head of Obstetrics and Gynaecology, Colonial War Memorial Hospital, personal (interquartile range). communication) as a denominator, the prevalence of RHD in pregnant women in Fiji was 1.8 per 1000 (95\% CI, 0.9-3.1).

There were 99 patients with echocardiographic information available. In these patients, the most commonly affected valve was the mitral valve (90 patients). Mitral stenosis occurred in 53 patients, with the youngest of these patients aged 12.9 years.

\section{DISCUSSION}

Our findings show that ARF and RHD are significant problems in Fiji, especially in Indigenous Fijians and young people. The incidence of ARF in 5-15-year-olds in our study is comparable to rates in various outbreaks described in the US in the 1980 s. $^{3,9,10}$ The clinical features of ARF in our patient group were also similar to those described during these outbreaks, particularly the high proportion of patients with carditis.

Comparison of our data for ARF incidence in children aged $5-15$ years (15.2 per 100000 ) with figures from previous reports from Fiji indicates that the incidence of ARF may be declining. ${ }^{11,12}$ In a study of ARF

\section{Clinical features of patients presenting with definite acute rheumatic fever to the Colonial War Memorial Hospital, December 2005 to November 2007}

\begin{tabular}{|c|c|c|c|c|}
\hline & \multicolumn{2}{|c|}{ Cases } & \multicolumn{2}{|c|}{ Episodes } \\
\hline & All & All non-chorea* & Initial & Recurrent \\
\hline Number of patients & 33 & 29 & 20 & 13 \\
\hline 2 or more major manifestations & 14 & 13 & 8 & 6 \\
\hline 1 major manifestation & 19 & 16 & 12 & 7 \\
\hline Carditis & 26 & 25 & 15 & 11 \\
\hline Pericarditis & 3 & 3 & 2 & 1 \\
\hline Cardiac failure & 3 & 3 & 1 & 2 \\
\hline Polyarthritis & 17 & 16 & 11 & 6 \\
\hline Chorea & 5 & 1 & 3 & 2 \\
\hline Erythema marginatum & 1 & 1 & 0 & 1 \\
\hline Subcutaneous nodules & 0 & 0 & 0 & 0 \\
\hline Fever & 22 & 21 & 14 & 8 \\
\hline Monoarthritis & 4 & 4 & 2 & 2 \\
\hline Polyarthralgia & 7 & 7 & 3 & 4 \\
\hline Raised inflammatory markers & 30 & 28 & 18 & 12 \\
\hline Prolonged PR on electrocardiogram & 2 & 2 & 0 & 2 \\
\hline Recent sore throat (within 14 days) & 14 & 12 & 10 & 4 \\
\hline Positive group A streptococcal throat culture & 4 & 4 & 2 & 2 \\
\hline Peak temperature $\left({ }^{\circ} \mathrm{C}\right)^{\dagger}$ & $\begin{array}{c}38.4 \\
(37.6-38.9)\end{array}$ & $\begin{array}{c}38.5 \\
(37.8-38.9)\end{array}$ & $\begin{array}{c}38.2 \\
(37.6-38.9)\end{array}$ & $\begin{array}{c}38.5 \\
(37.6-39.2)\end{array}$ \\
\hline Peak ESR $(\mathrm{mm} / \mathrm{h})^{\dagger}$ & $\begin{array}{c}85 \\
(45-118)\end{array}$ & $\begin{array}{c}100 \\
(63-120)\end{array}$ & $\begin{array}{c}88 \\
(40-114)\end{array}$ & $\begin{array}{c}85 \\
(60-120)\end{array}$ \\
\hline Peak ASO titre $(\mathrm{IU} / \mathrm{mL})^{\dagger}$ & $\begin{array}{c}392 \\
(314-542)\end{array}$ & $\begin{array}{c}399 \\
(314-575)\end{array}$ & $\begin{array}{c}363 \\
(288-487)\end{array}$ & $\begin{array}{c}456 \\
(368-575)\end{array}$ \\
\hline Peak ADB titre $(\mathrm{IU} / \mathrm{mL})^{\dagger}$ & $\begin{array}{c}400 \\
(300-800)\end{array}$ & $\begin{array}{c}400 \\
(300-800)\end{array}$ & $\begin{array}{c}600 \\
(300-800)\end{array}$ & $\begin{array}{c}400 \\
(350-800)\end{array}$ \\
\hline
\end{tabular}

$\mathrm{ESR}=$ erythrocyte sedimentation rate. $\mathrm{ASO}=$ antistreptolysin $\mathrm{O} . \mathrm{ADB}=$ antideoxyribonuclease $\mathrm{B} .{ }^{\star}$ Cases in which the diagnosis was not made on the basis of chorea alone. $†$ Figures for peak measurements are median 


\section{Clinical features of 103 patients presenting with rheumatic heart disease to the Colonial War Memorial Hospital, December 2005 to November 2007}

\begin{tabular}{lr} 
Clinical presentation & No. \\
\hline Cardiac failure & 33 \\
Cardiac failure secondary to & 28 \\
valvular disease & \\
Cardiac failure secondary to & 5 \\
atrial fibrillation & \\
Rheumatic heart disease in pregnancy & 24 \\
Cardiac failure secondary to & 16 \\
valvular disease & \\
Monitoring of rheumatic heart disease & 4 \\
Cardiac failure secondary to & 2 \\
atrial fibrillation & \\
New murmur in pregnancy & 2 \\
Recurrence of rheumatic fever & 9 \\
Infective endocarditis & 11 \\
Atrial fibrillation & 10 \\
Stroke & 9 \\
Stroke secondary to valvular & 4 \\
heart disease & \\
Stroke secondary to atrial fibrillation & 3 \\
Stroke secondary to infective & 2 \\
endocarditis & \\
New murmur &
\end{tabular}

presentations to hospital in the Western Division of Fiji in 1965-1966, there were 193 admissions for ARF, equating to an annual incidence in children aged 5-14 years of 144 per $100000 .^{12}$ The reasons for this change in epidemiology are not clear. However, our data might underestimate the true incidence of ARF in Fiji because our study focused on inpatient admissions and therefore did not detect outpatient presentations, ${ }^{13,14}$ or because cases of ARF are not being recognised by health care workers, ${ }^{15,16}$ or because some cases of ARF are very mild and these patients do not present for medical care. ${ }^{4}$

The prospective systematic approach to the burden of RHD in hospital that we used in this study has not been carried out elsewhere, that we are aware of. However, it is also likely that our data have underestimated the true burden of RHD because hospital admission data only detect patients with severe symptomatic disease, missing outpatients and younger patients with latent RHD. Despite this, our data clearly show that RHD causes a considerable burden of disease in Fiji, accounting for 13 of 14 cases of infective endocarditis and nine of 234 strokes (3.8\%) during the study period, and causing significant morbidity in pregnant women.

Previous studies have found an inflated risk of ARF and RHD in Pacific Islanders, consistent with our findings. For example, the Maori population in New Zealand has a rate of ARF at least five times that of white New Zealanders; in Hawaii, Samoan children have a risk of ARF 88 times that of white children; and in the US, Asians and Pacific Islanders account for $6.3 \%$ of admissions for ARF, even though they account for only $2.0 \%$ of total admissions for any cause $(P<0.05)^{9,17,18}$ The reasons for this increased risk are not clear.

The young age of patients with established RHD, the high proportion of stenotic valvular lesions and the high recurrence rate of ARF found in this study all underline the need for effective control. Recently revitalised control efforts are now focused on improved delivery of, and compliance with, secondary prophylaxis, as well as case finding through screening for RHD in school children. ${ }^{15}$ Other control methods, including a group A streptococcal ARF vaccine, also need to be considered. We found that the incidence of ARF in Fiji was sufficiently high for it to be considered in the future as a clinical endpoint for group A streptococcal vaccine trials.

\section{ACKNOWLEDGEMENTS}

This study was supported by a grant from the US National Institutes of Health. We thank the Fiji Group A Streptococcal Project team for their assistance in surveillance, including Ms Laisiana Matatolu, Mrs Frances Matanatabu, Ms Maureen Ah-Kee and Ms Loraine Kelpie. Ms Roselyn Ritika processed all of the microbiological and serum samples. We also acknowledge the support provided by the Queensland Institute of Medical Research, in particular the Director, Professor Michael Good.

\section{COMPETING INTERESTS}

None identified.

\section{AUTHOR DETAILS}

Andrew C Steer, MB BS, BMedSci, FRACP, Clinical and Public Health Research Fellow ${ }^{1}$ Joseph Kado, MB BS, Paediatrician ${ }^{2}$

Adam W J Jenney, MB BS, PhD, FRACP, Infectious Diseases Physician ${ }^{1}$ Michael Batzloff, BSc, PhD, Laboratory Head ${ }^{3}$ Lepani Waqatakirewa, MB BS, Permanent Secretary of Health ${ }^{2}$

E Kim Mulholland, MB BS, FRACP, MD, Professor ${ }^{4}$

Jonathan R Carapetis, MB BS, FRACP, PhD, Director $^{4}$

1 Centre for International Child Health, University of Melbourne, Melbourne, VIC.
2 Fiji Ministry of Health, Suva, Fiji.

3 Bacterial Vaccines Laboratory, Queensland Institute of Medical Research, Brisbane, QLD.

4 Menzies School of Health Research, Charles

Darwin University, Darwin, NT.

Correspondence: andrew.steer@rch.org.au

\section{REFERENCES}

1 Carapetis JR, Steer AC, Mulholland EK, Weber M. The global burden of group A streptococcal diseases. Lancet Infect Dis 2005; 5: 685-694.

2 Tibazarwa KB, Volmink JA, Mayosi BM. Incidence of acute rheumatic fever in the world: a systematic review of population-based studies. Heart 2008; 94 1534-1540.

3 Ayoub EM. Resurgence of rheumatic fever in the United States. The changing picture of a preventable illness. Postgrad Med 1992; 92: 133-142.

4 Carapetis JR, Currie BJ. Rheumatic fever in a high incidence population: the importance of monoarthritis and low grade fever. Arch Dis Child 2001; 85: 223-227.

5 Carapetis JR, Steer AC, Mulholland EK. The current evidence for the burden of group A streptococcal diseases. Geneva: Department of Child and Adolescent Health and Development, World Health Organization, 2005.

6 Fiji Islands Bureau of Statistics. Statistical News. Press Release No. 52. Provisional results - 2007 Population and Housing Census. Suva: Government of Fiji, 31 Oct 2007.

7 Special Writing Group of the Committee on Rheumatic Fever, Endocarditis, and Kawasaki Disease of the Council on Cardiovascular Disease in the Young of the American Heart Association. Guidelines for the diagnosis of rheumatic fever. Jones Criteria, 1992 update. JAMA 1992; 268: 2069-2073.

8 World Health Organization Expert Consultation on Rheumatic Fever and Rheumatic Heart Disease. Rheumatic fever and rheumatic heart disease: report of a WHO Expert Consultation Geneva, 29 October - 1 November 2001. Geneva: WHO, 2004.

9 Chun LT, Reddy DV, Yamamoto LG. Rheumatic fever in children and adolescents in Hawaii. Pediatrics 1987; 79: 549-552

10 Veasy LG, Wiedmeier SE, Orsmond GS, et al. Resurgence of acute rheumatic fever in the intermountain area of the United States. N Engl J Med 1987; 316: 421-427.

11 Neutze JM. Rheumatic fever and rheumatic heart disease in the western Pacific region. N Z Med J 1988; 101: 404-406.

12 Negus RM. Rheumatic fever in Western Fiji: the female preponderence. Med J Aust 1971; 2: 251254.

13 Loeffler AM, Neches WH, Ortenzo M, et al. Identification of cases of acute rheumatic fever managed on an outpatient basis. Pediatr Infect Dis J 1995; 14: 975-978.

14 Wolfe RR. Incidence of rheumatic fever. J Pediatr 1993; 122: 327-328.

15 Steer AC, Kado J, Colquhoun S, et al. Awareness of rheumatic heart disease. Lancet 2006; 367: 2118.

16 Mataika R, Carapetis JR, Kado J, Steer AC. Acute rheumatic fever: an important differential diagnosis of septic arthritis. J Trop Pediatr 2008; 54: 205-207.

17 Neutze JM, Clarkson PM. Rheumatic fever: an unsolved problem in New Zealand. N Z Med J 1984; 97: 591-593.

18 Miyake CY, Gauvreau K, Tani LY, et al. Characteristics of children discharged from hospitals in the United States in $\mathbf{2 0 0 0}$ with the diagnosis of acute rheumatic fever. Pediatrics 2007; 120: 503-508.

(Received 26 May 2008, accepted 13 Oct 2008) 口 